\title{
Association of Chlamydia serology with HIV in Nigerian women
}

\author{
${ }^{* 1}$ H. I. D. Muhammad, ${ }^{1}$ E. D. Jatau, ${ }^{1}$ O. S., Olonitola, ${ }^{2 M}$. A. Abdul, ${ }^{1}$ M. S. Aliyu, ${ }^{1}$ M. B. Tijjani \\ 1Department of Microbiology, Ahmadu Bello University, Zaria \\ ${ }^{2}$ Department of Obstetrics and Gynaecology, Ahmadu Bello University Teaching Hospital, Zaria \\ [ ${ }^{*}$ Corresponding author: E-mail: egidoko@yahoo.com; P: 08065162864]
}

\begin{abstract}
This research was carried out to detect the presence of Chlamydia in pregnant women and gynaecologic patients in the North-central geopolitical zone of Nigeria. Blood samples were collected and analysed by ELISA techniques. The blood samples were also screened for HIV infection. A seroprevalence of $59.0 \%$ was recorded for the study area. The sero-prevalence was higher among the gynaecologic patients $(62.0 \%)$ than the pregnant women $(57.5 \%)$. The difference was statistically significant $(P=0.0001)$. Of the four centers chosen for the study, the Federal Capital Territory (Abuja) had the highest prevalence $(84.7 \%)$, while Niger State had the least $(28.7 \%)$. The difference was also statistically significant $(P<0.0001)$. The prevalence rate of HIV among the participants in the study center was found to be $17.2 \%$. Abuja had the highest prevalence rate of $24.6 \%$, followed by Benue, $16.7 \%$, then Kogi, $12.0 \%$ and finally, Niger, $4.7 \%$. Chlamydia was found to be associated with HIV $(p<0.0001)$. The sero-prevalence of chlamydia in the North-Central zone of Nigeria was found to be high. Chlamydia was found to be correlated with HIV in the study area and may have contributed to the zone emerging with the highest HIV prevalence in the country. For an infection that is largely asymptomatic but has devastating effects on populations, only a preventive approach would have beneficial effects in controlling the disease and its effects on women's health in the country.
\end{abstract}

Keywords: Chlamydia trachomatis, HIV, pregnant women, gynaecologic patients, co-infection

\section{INTRODUCTION}

Chlamydial infection is the most common curable bacterial sexually transmitted disease (CDC, 2006; WHO, 2011). The incidence of chlamydial infections in women has increased dramatically from 79 to 467 per 100,000 between 1987 and 2003 (Sexually transmitted disease surveillance, 2004). According to the World Health Organization (WHO, 2011), 101 million chlamydial infections are detected annually worldwide. In the U.S. the Centres for Disease Control and Prevention (CDC) estimates that 2.8 million people are infected each year (CDC, 2006). In some parts of the third-world countries, more than 90 per cent of the population is infected (Gomes et al., 2007). Chlamydial infection is caused by Chlamydia trachomatis, a coccoid bacillus closely related to Gram negative bacteria (Cheesbrough, 2000). Chlamydia trachomatis belongs to the genus Chlamydia which includes organisms previously called the Psittacosis Lymphogranuloma venerum Trachoma group (PLT) or the TRIC (TRachoma Inclusion
Conjunctivitis group) (Mackie \& Mac Cartney, 1989).

Chlamydia trachomatis has 15 immunotypes (serotypes) viz; A-C which cause trachoma (chronic conjunctivitis endemic in Africa and Asia), D-K, which cause genital tract infection and L1-L3 responsible for lymphogranuloma venerum (associated with genital ulcer disease in tropical countries). Chlamydia trachomatis serovars $\mathrm{D}-\mathrm{K}$ cause curable sexually transmitted disease called Chlamydia (CDC, 2006). The disease which arises from the infection of the lower genital tract is one of the most prevalent sexually transmitted diseases in the world (Gerbase et al., 1998; Beagley and Timms, 2000). It is usually asymptomatic, in fact $50 \%$ of men and $80 \%$ of women are asymptomatic, and for this reason it is referred to as silent disease (Gaydos et al., 1998; CDC, 2006; Ward et al., 2007). In cases where symptoms are present they may last only a few days and may not be noticed or considered significant (Kidshealth, 2006). Clinical symptoms in women, where present include 
vaginal discharge, dysuria, easily induced endocervical bleeding, irregular menstruation or intermenstrual bleeding, dyspareunia, lower abdominal pain, genital itching, increased urination frequency and sore in the vagina (CDC, 2006; Al-Mutairi et al., 2007).

Chlamydia is one of the non - ulcerative sexually transmitted infections which elicit localised inflammations and immune responses characterised by the infiltration and accumulation of immune cells expressing CD4 surface proteins essential for the binding of HIV prior to entry, thus also facilitating the entry of HIV (Altes et al., 2002; Joyee et al., 2005; Wodarz and Hamer 2007). In a study conducted in the South- Eastern part of Nigeria by Nwaguma et al. 2009, it was found out that the prevalence of $C$. trachomatis infection observed in the HIV - seropositive subjects $(50 \%)$ was much higher than the prevalence in the HIV-seronegative subjects (17.6\%) (Nwaguma et al., 2009).

Chlamydia, if left untreated can persist for at least 15 months (Mc Cormack et al., 1979) and can have potentially serious lifetime consequences which include pelvic inflammatory disease (PID) (Stamm et al., 1984, Land, 2010). PID is a general term that refers to infection and inflammation of the upper genital tract in women. It can affect the uterus (womb), fallopian tubes, ovaries and other organs related to reproduction (Moss, 2001). In USA, approximately 20-30 per cent of PID cases have been attributed to $C$. trachomatis (Soper, 2010). The incidence rates of PID in Nigeria vary between 0.28 and $4.4 \%$ of deliveries (lloabachi, 1990). Sequelae of PID include ectopic pregnancy and tubal infertility (Buchan et al., 1993). The risk of developing sequelae is dependent on the number of PID episodes (Westrom, 1994). Epidemiological studies have shown that sexually transmitted pathogens, including non-ulcerative agents such as $C$. trachomatis, may serve as biological cofactors for human immunodeficiency virus (HIV) seroconversion (Plummer et al., 1991; Laga et al., 1993; Grosskurth et al., 1995). However, basic data, such as the incidence and prevalence of many sexually transmitted diseases (STDs), which are necessary for obtaining estimates of their impact on sexual transmission of HIV, are relatively scarce in developing countries. In many areas, diagnosis of C. trachomatis genital infection is only performed in selected populations and is often based on the presence of clinical symptoms. Considering the high rate of asymptomatic chlamydial infection, particularly in women, a substantial "silent" or undetected epidemic of $C$. trachomatis infections could put this population at significant risk for HIV infection. A reliable epidemiological data is needed to determine the prevalence rate of the disease in the populations which will help in devising an effective chlamydia control program. It is in view of the above that this research work was carried out to detect the presence of Chlamydia in pregnant women and gynaecologic patients in the North-central geopolitical zone of Nigeria and to check the rate of occurrence of Chlamydia - HIV co-infection.

\section{METHODOLOGY}

By simple random sampling method, three states (Benue, Kogi and Niger) and the Federal Capital Territory were selected from the NorthCentral geo-political zone. The Federal Medical Centers, Makurdi, and Kogi, the National Hospital, Abuja and the General Hospital Minna were chosen for the study. The study groups comprised 400 pregnant women and 200 gynaecologic patients attending the gynecological clinics for PID, infertility and ectopic pregnancy. Only those who had not been on antibiotics (azithromycin, erythromycin, doxycycline, or tetracycline) in the past three months before sampling were included in the study. Each subject gave her consent and the study was approved by the Ethical Committees of the Hospitals. Data were analyzed using Chisquare test and $P \leq 0.05$ was considered statistically significant.

\section{Blood sample collection}

Five (5) ml of blood sample was collected from each participant by venepuncture and stored in venoject vacutaneers and allowed to clot. The sera were separated by spinning the blood in a 
centrifuge at $3000 \mathrm{rpm}$ and stored at $-20^{\circ} \mathrm{C}$ till use.

\section{Anti - Chlamydia trachomatis ELISA \\ Chlamydia trachomatis IgG ELISA test kit by DIAGNOSTIC AUTOMATION, INC, Calabasas was used. It employs the LGV type 2 broadly reacting antigen of Chlamydia trachomatis. It detects Chlamydia trachomatis, Chlamydia psittaci and Chlamydia pneumonia (TWAR) antibodies. It was performed according to the manufacturer's instruction.}

\section{Test for HIV}

Determine kits for the test of HIV1/2 manufactured by Alere Medical Co. Japan were used to screen the blood samples. It is an in vitro, visually read, qualitative immunoassay for the detection of antibodies to HIV-1/2 in human serum, plasma or whole blood. The Determine positive samples were further tested using HIV 1/2 STAT-PAK DIPSTICK kit manufactured by Chembio Diagnostic Systems, INC, USA. Both tests were carried out according to the manufacturers' instructions.

\section{RESULTS}

The study population was made up of two groups, pregnant women and gynaecologic patients. Of the 400 pregnant women tested, 230 were positive for Chlamydia IgG with a prevalence rate of $57.5 \%$ while 124 out of the 200 gynaecologic patients tested positive giving a prevalence rate of $62.0 \%$. The results are as shown in Table 1.

The six hundred blood samples constituted one hundred and fifty (150) from each of the Federal Capital Territory (Abuja), Benue, Kogi and Niger States. Of the 150 samples from each study center, 100 were from pregnant women and 50 from gynaecologic patients. Of the 150 samples assayed from each of the centers, 127, 107, 77 and 43 samples were found positive for the Federal Capital Territory (Abuja), Benue, Kogi and Niger States respectively giving prevalence rates of $84.7 \%, 71.3 \% 51.3 \%$ and $28.7 \%$ respectively. The sero-prevalence of Chlamydia IgG antibodies in parts of the North-Central Nigeria is shown in Table 2.

All the participants in the study groups were also screened for HIV to determine the relationship between Chlamydia and HIV in them. Of the 600 samples tested for HIV, 103 were positive giving a prevalence rate of $17.2 \%$. Abuja had the highest prevalence rate of $24.6 \%$ (37 in 150), followed by Benue, 16.7\%, (25 in $150)$ then Kogi, $12.0 \%$ (18 in 150) and finally, Niger, $4.7 \%$ (07 in 150). The results of HIV prevalence in the North Central are shown in Table 3.

As for relationship between Chlamydia and HIV, 61 subjects tested positive for both Chlamydia and HIV, 293 were positive for Chlamydia only, while 18 had only HIV. Results are shown in Table 4.

Table 1: Seroprevalence of Chlamydia IgG antibodies in parts of the North-Central Nigeria based on the study groups

\begin{tabular}{lccc}
\hline Group & No. Screened & No. Pos & \% Prevalence \\
\hline Pregnant & 400 & 230 & 57.5 \\
Gynaecologic & 200 & 124 & 62.0 \\
Total & 600 & 354 & 59.0 \\
\hline$X^{2}=1.11$ & & &
\end{tabular}

$\mathrm{X}^{2}=1.11 \quad \mathrm{P}=0.292$

Table 2: Seroprevalence of Chlamydia IgG antibodies in parts of the North-Central Nigeria

\begin{tabular}{lccc}
\hline Part & No. Screened & No. Positive & \% Prevalence \\
\hline Abuja & 150 & 127 & 84.7 \\
Benue & 150 & 107 & 71.3 \\
Kogi & 150 & 77 & 51.3 \\
Niger & 150 & 43 & 28.7 \\
\hline
\end{tabular}

$\mathrm{X}^{2}=111,(\mathrm{P}<0.0001)$ 
Muhammad et al: Association of Chlamydia serology with HIV in Nigerian women

Table 3: Prevalence of HIV 1/2 among the study participants in parts of the North-central

\begin{tabular}{crrr}
\hline & No. Screened & No. Positive & \% prevalence \\
\hline Abuja & 150 & 37 & 24.6 \\
Benue & 150 & 25 & 16.7 \\
Kogi & 150 & 18 & 12.0 \\
Niger & 150 & 07 & 4.7 \\
Total & 600 & 87 & 14.5 \\
\hline
\end{tabular}

Table 4: Relationship between Chlamydia and HIV in parts of the North Central

\begin{tabular}{lccc}
\hline & No. Screened & Positive & \%prevalence \\
\hline All Chlamydia & 600 & 354 & 59.0 \\
All HIV & 600 & 79 & 13.2 \\
Chlamydia only & 600 & 293 & 48.8 \\
HIV only & 600 & 18 & 3.0 \\
Chlamydia and HIV & 600 & 61 & 10.2 \\
\hline$X^{2}=779.7$ & &
\end{tabular}

$\mathrm{X}^{2}=779.7 \quad \mathrm{p}<0.0001$

\section{DISCUSSION}

The seroprevalence of Chlamydia IgG antibody in parts of the North central Nigeria was found to be $59.0 \%$ in this study. This high prevalence is in line with the report by (CDC) in 2005 that in the United States, chlamydial genital infection is the most frequently reported infectious disease, and the prevalence is highest in persons aged $<25$ years (CDC, 2005). It is also similar to the findings of Mawak et al., 2011 and Dibua et al., 2013 which was $56.1 \%$ among gynaecologic clinic attendees in Jos and Nsukka respectively. A $51.0 \%$ prevalence among pregnant and nonpregnant women and their spouses attending pre and antenatal clinic in the College of Medicine of the University of Lagos has been reported (Okoror et al., 2000). A slightly lower prevalence of $40.7 \%$ of $C$. trachomatis has also been reported from the South-Eastern part of Nigeria (Okoror et al., 2007). Other lower prevalences of $38.3 \%$ in Zaria (Tukur et al., 2006 ) and $13.3 \%$ in Benin City (Isibor et al., 2005) have also been reported.

The high prevalence found in this part of the country in this study can be considered as an evidence of endemicity in the population and this may be due to the fact that Chlamydia infections usually present with no clear cut symptoms and are as a result left untreated or mistaken for other infections such as gonorrhoea. This often leads to serious sequelae such as pelvic inflammatory disease
(PID), endometrirtis, salpingitis, ectopic pregnancy and infertility (Mabey et al., 1992).

Other factors that could be attributable to the high prevalence and endemicity are sociocultural inhibition that prevents women from reporting sexual symptoms and nonavailability of facility to detect the causative agent (Chlamydia trachomatis) in many health care centres in this part of the world (Okonofua et al., 1995). The high prevalence could have also been caused by the high prevalence of HIV-AIDS in the area. According to the Technical Report of the 2010 National HIV Sero-prevalence Sentinel Survey, the Northcentral geopolitical zone had the highest prevalence rate of AIDS and studies have shown the association between the two infections (chlamydia and HIV) such that the presence of one facilitates that of the other. Genital Chlamydia infection has been linked to an increasing risk for acquisition of HIV disease (Laga et al., 1993; Ho et al., 1995; Brunham, et al., 1996; Stamm, 1999; Joyee, et al., 2005) while on the other hand, immunosuppresion due to HIV may lead to more severe Chlamydia disease condition like PID in those who are infected with Chlamydia trachomatis (Thomas, et al., 2002). Thus early diagnosis and treatment of Chlamydia infections is important to prevent HIV risk and devastating clinical consequence. The two infections (Chlamydia and HIV infections) have also being reported to have common risk factors, for instance, Joyee, 
et al., (2005) reported that both HIV and Chlamydia are significantly associated with some risk factors such as multiple sexual partners.

The possible relationships between HIV infection and Chlamydia trachomatis are that the invasive intracellular pathogenesis of Chlamydia trachomatis can cause substantial damage to the genital epithelial layer which may facilitate HIV infection (Hitchcock, 1999) and immunological changes due to HIV infection may favor Chlamydia trachomatis (Debattista et al., 2002). Chlamydia is one of the non - ulcerative sexually transmitted infections which elicit localised inflammations and immune responses characterised by the infiltration and accumulation of immune cells expressing CD4 surface proteins essential for the binding of HIV prior to entry, thus also facilitating the entry of HIV (Altes et al., 2002; Joyee et al., 2005; Wodarz and Hamer, 2007).

The results of this study also showed that the prevalence of Chlamydia was slightly higher among gynaecologic cases $(62.0 \%)$ than in the pregnant women (57.5\%). This is similar to an earlier report in Delta State by Omo-Aghoja et al. (2007), that the prevalence of serum Chlamydia antibody was significantly higher in cases $(65.8 \%)$ (tubal infertility) compared with controls (pregnant women) $(17.3 \% ; P<0.01)$. Although it is not recommended for the diagnosis of lower genital tract infections, or for screening in asymptomatic patients, serological testing has been shown to be useful for diagnosing LGV, neonatal pneumonia and upper genital tract infections, and for the evaluation of tubal-factor infertility (Persson, 2002; Be'be'ar and de Barbeyrac, 2009).

Conclusively, the sero-prevalence of chlamydia in the North-Central zone of Nigeria was found to be high and it was found to be associatedted with HIV in the study area and may have contributed to the zone emerging with the highest HIV prevalence in the Country. Future studies are required to investigate the genotypes of chlamydia in circulation in the study population and to investigate the role of
Chalmydia trachomatis genotypes in disease manifestations.

\section{REFERENCES}

Al-Mutairi, N., Joshi, A., Nour-Eldin, O., Sharma, A. K., el-Adawy T. and Rijhwani, M. (2007). Clinical patterns of sexually transmitted diseases: associated sociodemographic characteristics and sexual prsctices in the Farwaniya Region of Kuwait. International Journal of Dermatology, 46(6): 594599.

Altes, H. K., Wodarz, D. and Jansen, V. A. (2002). The dual role of $T$ helper cells in the infection dynamics of HIV and their importance for vaccination. Journal of Theoretical Biology, 214: 633 - 646.

Beagley, K. W. and Timms, P. (2000). Chlamydia trachomatis infection: incidence, health costs and prospects for vaccine development. Journal of Reproduction and Immunology, 48(1):47-68.

Be'be'ar C. and de Barbeyrac, B. (2009). Genital Chlamydia trachomatis infection. Clinical Microbiology and Infection, 15(1) 4-10.

Brunham, R.C., Kimsanij, Bwayol, Malthu, G, Maaclean, I., Tangc, Shenc, Romans, Negkerke, N.S.D., Chcaj, M. and Plummer, F. A. (1996). The Epidemiology of Chlamydia Trachomatis Within a Sexually Tramitted Disease are Group. Journal of Infection Disease, 173:950-956.

Buchan, H, Vessey, M., Goldacre, M. and Fairweather, J. (1993). Morbidity following pelvic inflammatory diseases British Journal of Obstetrics and Gynaecology, 1000:558-562.

Centers for Disease Control and Prevention. (2005). Sexually Transmitted Disease Surveillance, 2004. Atlanta, GA: U.S. Department of Health and 
Human Services, CDC, National Centre for HIV, STD, and TB Prevention.

Centers for Disease Control and Prevention. (2006). Chlamydia fact sheet, sexually transmitted diseases. www.cdc.gov/std/chlamydia/STDFa ct-chlamydia.htm. Accessed: April, 2006

Cheesbrough, M. (2000). District Laboratory Practice in Tropical Countries, Part 2. Cambridge low price edition. Pp: 232-234

Debattista, J., Clementson C., Mason D., Dioyer J., Argent S., Woodward, C., Dean, J., Bucks, L., Copley, M., Hinwood, G., Benfield, C. and Walton, P. (2002). Screening for Neisseria gonorrhoeae and Chlamydia trachomatis at entertainment venues among man who have sex with men. Sexually Transmitted Diseases. 29: 216 221.

Dibua, Uju M. E., Ugonabo, J. A. C., Oladepo, D., Iroha, I. R. and Odimegwu, N. D. (2013). Genital Chlamydia and HIV co-infection: adverse pregnancy outcomes. American Journal of Research Communication, 1(12): 470-500.

Gaydos, C. A., Howell, M. R., Pare, B. and Clark, K. L. Ellis, D. A. Hendrix, R. M. Gaydos, J. C., McKee, Jr., K. T. and Quinn, T. C. (1998). Chlamydia trachomatis Infections in Female Military Recruits. New English Journal of Medicine, 339: 739-744.

Geneva: World Health Organization; 2011. Global prevalence and incidence of selected curable sexually transmitted diseases: Overview and estimates.

Gerbase, A. C., Rowley, J. T., Heyman, D. H., Berkley, S. F. and Piot, P. (1998). Global prevalence and incidence estimates of selected curable sexually transmitted diseases. Sexually Ttransmitted Infections, 74: 512-516.
Gomes, J. P., Bruno, W. J., Nunes, A., Saints, N., Floridao, C., Borrego, M. J. and Dean, D. (2007). Evolution of Chlamydia trachomatis diversity occurs by wide spread inter strain recombination involving hotspots. Genome Research, 17:50-60.

Grosskurth, H. Mosha F, Todd J, Mwijarubi E, Klokke A, Senkoro K, Mayaud $P$, Changalucha J, Nicoll A, ka-Gina G., Newell, J., Mugeye, K., Mabey, D., and Hayes, R. (1995). Impact of improved treatment of sexually transmitted diseases on HIV infection in rural Tanzania: randomised controlled trial. Lancet. 346: $530-536$.

Hitchcock, P. J. (1999). Future directions of chlamydial research. In:Stephens RS, Ed. Chlamydia: intracellular biology, pathogenesis, and immunity. (American Society for Microbiology, Washington DC). 297311.

Ho, J. L., S. He, A. Hu, J. Geng, F. G. Basile, M. G. Almeida, A. Y. Saito, J. Laurence. and W. D. Johson, Jr. (1995). Neutrophils from human immunodeficiency virus (HIV)seronegative donors induce HIV replication from HIV-infected patient's mononuclear cells and cell line: an in vitro model of HIV transmission facilitated by Chlamydia trachomatis. Journal of Experimental Medicine. 181: 14931505.

lloabachi, G. C. (1990). Tubal ectopic pregnancies and the intrauterine devices. Tropical Journal of Obstetrics and Gynaecology, 8: 2023.

Isibor, J. O., Ugbomoiko, D., Nwobu, G. O., Ekundayo, A. O., Enweani, I. B. and Okogun, G. R. A. (2005). Detection of chlamydia antigen in cervical specimens from antenatal clinic attendees in Benin City, Nigeria. African Journal of Clinical 
and Experimental Microbiology.

6(3): 208-211.

Joyee, A. C., Thyagarajan, S. P., Riddy, E. V., Venkatesan, C. and Ganapathy, M. (2005). Chlamydia infection in patients: its relation to HIV infection. Indian Journal of Medical Microbiology; 23: 37 - 40.

Kidshealth for Parents (2006). Infections: chlamydial infections. http//www.kidshealth.org/parent/infe ctions/bacterial_viral/Chlamydia.htm I.

Laga, M., Manoka, A., Kivuvu, M., Malele, B., Tuliza, M., Nzila, N., Goeman, J., Batter, V. and Alary, M. (1993). Non-ulcerative sexually transmitted diseases as risk factors for HIV-1 transmission in women: results from a cohort study. AIDS 7:95-102.

Land, J. A. (2010). Epidemiology of Chlamydia trachomatis infection in women and the cost-effectiveness of screening. Human Reproduction Update 16(2):189-204.

Mabey, D. C., Bailey, R. L., Ward, M. E. and Whittle, H. C. (1992). A longitudinal study of trachoma in a Gambian village: implications concerning the pathogenesis of chlamydial infection. Epidemiology and Infection. 108(2):343-151.

Mackie and Mc Cartney (1989). Medical Microbiology, a guide to the laboratory diagnosis and control of infections, Vol. 1: Microbial Infections. 13 $13^{\text {th }}$ Edition. English Language Book Society/ Churchill Livingstone.

Mawak, J. D., Dashe, N., Agabi, Y. A., and Panshak, B. W. (2011). Prevalence of Genital Chlamydia trachomatis Infection among Gynecologic Clinic Attendees in Jos, Nigeria. Shiraz EMedical Journal 12(2): 1-9

Mc Cormack, W. M., Alpert, S., Mc DE., Nicholas, R. I., Samine, D. Z. and Zinner, S. H. (1979). Fifteen-month follow-up study of women infected with Chlamydia trachomatis. New
English Journal of Medicine, 339: 739-744.

Moss, T. R. (2001). International Hand book of Chlamydia. Polester Wheatons Ltd. Exeter U.K.

National HIV Sero-prevalence Sentinel Survey. (2010). Technical Report. Federal Ministry of Health, Nigeria, Department of Public Health, National AIDS/STI control Programme. 1-110.

Nwaguma, B. C., Kalu, I. and Ezeanyika, L. S. (2009). Seroprevalence of antiChlamydia trachomatis IgA antibody in a Nigerian population: diagnostic significance and implications for the heterosexual transmission of HIV. The Internet Journal of infectious Diseases, (7)2.

Okonofua, F. E., Ako-Nai, K. A. and M. D. Dighitoghi. (1995). Lower genital tract infections in infertile Nigerian women compared with controls. Genitourinary Medicine. 71(3): 163168.

Okoror, L. E., Omilabu, S. A., Fadojutimi, J. and Nsongkhai, V. (2000). Seroepidemiological survey of Chlamydia in patients attending pre and post natal clinic at the College of Medicine of the University of Lagos, Nigeria. In: Book of Abstract of the 24th annual conference of the Nigerian Society for Microbiology.

Okoror, L. E., Agbonlahor, D. E., Esumeh, F. I., and Umolu, P. I. (2007). Prevalence of Chlamydia in patients attending gynaecological clinics in south eastern Nigeria. African Health Science, 7 (1): 18-24.

Omo-Aghoja, L. O., Okonofua, F. E., Onemu, S. O., Larsen, U. and Bergstrom, S. (2007). Association of Chlamydia trachomatis serology with tubal infertility in Nigerian women. Journal of Obstetrics and Gynaecology Research, 33(5): 688-695. 
Persson, K. (2002). The Role of serology, antibiotic susceptibility testing and serovar determination in genital chlamydial infections. Best Practice and Research Clinical Obstetrics and Gynaecology. 16(6):801-814.

Plummer, F. A., Simonsen, J. N., Cameron, D. W., Ndiaya - Achola, J. O. Kreiss, J. K., Gakinya, M. N., Waiyaki P., Cheang, M., Piot, P., Ronald, A. R. and Ngugi, E. N. (1991). Co factors in male - female sexual transmission of Human Immunodeficiency Virus Type 1. Journal of Infectious diseases, 163:233-239

Sexually transmitted disease surveillance 2003 supplement. Division of STD Prevention 2004, Deapartment of Health and Human Services, CDC, Atlanta

Soper, D. E. (2010). Pelvic inflammatory disease. Obstetrics and Gynecology. 116:419-428.

Stamm, W., Guinan, M., Johnson, C., Starcher, T., Holmes, K. and Mc Cormack, W. (1984). Effect of treatment regimens for Neisseria gonorrhoeae on simultaneous infection with Chlamydia trachomatis. New English Journal of Medicine, 310:545-549.

Stamm, W. E. (1999). Chlamydia trachomatis infections: progress and problems. Journal of Infectious Diseases, 179 (2):380-383.

Thomas, K. And Simmus, I. (2002). Chlamydia trachomatis in subfertile women undergoing uterine instrumentation. How can we help in avoidance of iatrogenic pelvic inflammatory disease. Human Reproduction, 17:1431-1436.

Tukur, J., Shittu, S.O. and Abdul, M. A. (2006). A case control study of active genital Chlamydia trachomatis infection among patients with tubal infertility in Northern Nigeria. Tropical Doctor, 36: 14-16.
Ward, H., Martin, I., Macdonald, N., Alexander, S., Simms, I., Fenton, K., French, P., Dean, G. and Ison, C. (2007). Lymphogranuloma venereum in the United Kingdom. Clinical Infectious Diseases, 44(1): 26-32.

Westrom, L. (1994). Sexually transmitted diseases and infection. Sexually Transmitted Diseases, 21:S32 S37.

Wodarz, D. and Hamer, D. H. (2007). Infection dynamics in HIV - specific CD4 T cell boost benefit the host or the virus? Mathematical Biosciences, 209: $14-29$.

World Health Organization (2011). Prevalence and incidence of selected sexually transmitted infections, Chlamydia trachomatis, Neisseria gonorrhoeae, syphilis, and Trichomonas vaginalis: methods and results used by WHO to generate 2005 estimates. Geneva, 2011. 